\title{
TRANSFORMASI BOX-COX PADA ANALISIS REGRESI LINIER SEDERHANA
}

\author{
ELVI YATI, DODI DEVIANTO, YUDIANTRI ASDI \\ Program Studi Matematika, \\ Fakultas Matematika dan Ilmu Pengetahuan Alam, Universitas Andalas, \\ Kampus UNAND Limau Manis Padang, Indonesia, \\ lviyati@ymail.com
}

\begin{abstract}
Abstrak. Asumsi dasar regresi merupakan asumsi yang harus dipenuhi dalam memodelkan hubungan antara variabel tak bebas $(Y)$ dengan variabel bebas $(X)$ dalam analisis regresi linier sederhana. Jika asumsi tersebut tidak dipenuhi, maka dapat dilakukan transformasi Box-Cox terhadap variabel tak bebas, dimana $Y$ dipangkatkan dengan $\lambda$, sehingga menjadi $Y^{\lambda}$. Pendugaan parameter $\lambda$ dilakukan dengan Metode Kemungkinan Maksimum dimana dipilih $\lambda$ yang memiliki jumlah kuadrat sisaan paling kecil. Parameter $\lambda$ tersebut digunakan dalam transformasi sehingga diperoleh data yang memenuhi asumsi normalitas, homogenitas, dan linieritas.
\end{abstract}

Kata Kunci: Metode kemungkinan maksimum, transformasi Box-Cox.

\section{Pendahuluan}

Analisis regresi adalah teknik statistika yang digunakan untuk membentuk model hubungan antara variabel bebas dengan variabel tak bebas. Hubungan antara satu variabel bebas $(X)$ dengan satu variabel tak bebas $(Y)$ untuk analisis regresi linier sederhana dinyatakan dalam model berikut

$$
Y_{i}=\beta_{0}+\beta_{1} X_{i}+\varepsilon_{i}
$$

Dalam analisis regresi linier sederhana perlu diperhatikan beberapa asumsi yang dikenal dengan asumsi dasar regresi yaitu asumsi kenormalan data (normalitas), kehomogenan ragam (homogenitas), dan kelinieran data (linieritas). Apabila kenormalan data, kehomogenan ragam dan kelinieran tidak dipenuhi, maka dapat dilakukan transformasi terhadap variabel tak bebas. Salah satu transformasi yang dapat dilakukan adalah Transformasi Box-Cox yang diberlakukan terhadap variabel tak bebas $Y$ yang bernilai positif. Transformasi Box-Cox ini berupa transformasi pangkat berparameter tunggal, katakanlah $\lambda$, terhadap $Y$ menjadi $Y^{\lambda}$. Pendugaan parameter $\lambda$ dapat dilakukan dengan menggunakan Metode Kemungkinan Maksimum (Maximum Likelihood Methods). $\lambda$ yang diambil adalah $\lambda$ yang menghasilkan jumlah kuadrat sisaan terkecil [3]. 
116 Elvi Yati dkk.

\section{Analisis Regresi}

\subsection{Uji Asumsi Dasar Regresi}

Dalam analisis regresi linier sederhana terdapat beberapa asumsi yang harus dipenuhi, di mana asumsi ini disebut asumsi dasar regresi. Pengujian asumsi dasar dalam analisis regresi linier sederhana diuraikan sebagai berikut.

(a) Asumsi Normalitas (Kenormalan Data)

Pengujian asumsi normalitas dengan uji Kolmogorov-Smirnov dapat dinyatakan sebagai berikut

$H_{0}$ : Data mengikuti sebaran tertentu

$H_{1}$ : Data tidak mengikuti sebaran tertentu

Berdasarkan [6], statistik uji yang digunakan adalah

$$
D=\max \left|F_{0}(x)-S_{N}(x)\right|,
$$

di mana $F_{0}(x)$ adalah fungsi kumulatif sebaran, $S_{N}(x)$ adalah peluang kumulatif sampel, dan $N$ adalah banyak pengamatan. Kriteria untuk pengujian ini adalah tolak $H_{0}$ jika nilai $D_{\text {hitung }}$ lebih besar dari nilai $D_{\text {tabel }}$.

(b) Asumsi Homogenitas (Kehomogenan Ragam)

Pengujian asumsi homogenitas dengan uji Levene dapat dinyatakan sebagai berikut

$H_{0}: \sigma_{1}^{2}=\sigma_{2}^{2}=\cdots=\sigma_{k}^{2}$

$H_{1}: \sigma_{i}^{2} \neq \sigma_{j}^{2}$ paling tidak untuk satu pasang $(i, j)$

Misalkan variabel tak bebas $Y$ dengan ukuran sampel $N$ yang dibagi atas $k$ subgrup, dimana $N_{i}$ menyatakan ukuran sampel dari subgrup ke- $i$, maka statistik uji Levene [4] dinyatakan sebagai berikut

$$
W=\frac{(N-k) \sum_{i=1}^{k} N_{i}\left(\bar{Z}_{i .}-\bar{Z}_{. .}\right)^{2}}{(k-1) \sum_{i=1}^{k} \sum_{j=1}^{N_{i}}\left(Z_{i j}-\bar{Z}_{i .}\right)^{2}},
$$

di mana $Z_{i j}=\left|Y_{i j}-\bar{Y}_{i .}\right|, \bar{Y}_{i}$. adalah nilai tengah dari subgrup ke- $i . \bar{Z}_{i}$. menyatakan nilai tengah grup(kelompok) dari $Z_{i j}$ dan $\bar{Z}$.. menyatakan nilai tengah secara keseluruhan dari $Z_{i j}$. Kriteria untuk pengujian ini adalah tolak $H_{0}$ jika nilai $W>F_{\alpha, k-1, N-k}$.

(c) Asumsi Linieritas (Kelinieran Data)

Pengujian kelinieran dengan uji $\mathrm{F}$ dinyatakan sebagai berikut.

$H_{0}$ : terdapat hubungan yang linier antara variabel $X$ dan $Y$

$H_{1}$ : tidak terdapat hubungan yang linier antara variabel $X$ dan $Y$

Dari [1], statistik uji yang digunakan adalah

$$
F_{h i t}=\frac{\chi_{1}^{2} /(k-2)}{\chi_{2}^{2} /(n-k)},
$$


dengan:

$$
\begin{aligned}
\chi_{1}^{2} & =\sum \frac{y_{i}^{2}}{n_{i}}-\frac{\left(\sum y_{i j}\right)^{2}}{n}-b^{2}(n-1) s_{x}^{2}, \\
\chi_{2}^{2} & =\sum y_{i j}^{2}-\sum \frac{y_{i}^{2}}{n_{i}} \\
s_{x}^{2} & =\frac{n \sum_{i=1}^{n} x_{i}^{2}-\left(\sum_{i=1}^{n} x_{i}\right)^{2}}{n(n-1)} .
\end{aligned}
$$

Didefinisikan $y_{i j}$ sebagai nilai ke- $j$ bagi peubah acak $Y_{i}$, sementara $y_{i}$. adalah jumlah nilai-nilai $Y_{i}$ dalam contoh. Kriteria pengujian ini adalah tolak $H_{0}$ jika $F_{\text {hit }}>F_{\text {tabel }}$.

\subsection{Metode Kemungkinan Maksimum}

Metode kemungkinan maksimum (Maximum Likelihood Methods) adalah metode yang digunakan untuk menduga parameter-parameter dengan memaksimumkan fungsi kemungkinan yang dibentuk dari fungsi kepekatan peluang bersama beberapa peubah acak.

Fungsi kemungkinan maksimum adalah fungsi dari $\theta$ dilambangkan dengan $L(\theta)$. Jika $X_{1}, X_{2}, \cdots, X_{n}$ merupakan peubah acak dari $f\left(x_{i} ; \theta\right)$, maka

$$
L(\theta)=f\left(x_{1} ; \theta\right) f\left(x_{2} ; \theta\right) \cdots f\left(x_{n} ; \theta\right)=\prod_{i}^{n} f\left(x_{i} ; \theta\right)[1]
$$

Pandang model regresi dalam notasi matriks

$$
\mathbf{Y}=\mathbf{X} \beta+\varepsilon ; \varepsilon \sim N\left(0, \sigma^{2}\right)
$$

Untuk analisis regresi linier sederhana, persamaan (2.5) dapat ditulis dalam bentuk

$$
Y_{i}=\beta_{0}+\beta_{1} X_{i}+\varepsilon_{i} \quad ; \quad \varepsilon_{i} \sim N\left(0, \sigma^{2}\right)
$$

Dalam regresi linier sederhana, fungsi kemungkinannya dapat dituliskan

$$
L=L\left(\beta_{0}, \beta_{1}, \sigma^{2}\right)=\left(2 \pi \sigma^{2}\right)^{-\frac{n}{2}} \exp \left[-\frac{1}{2 \sigma^{2}} \sum_{i=1}^{n}\left(Y_{i}-\beta_{0}-\beta_{1} X_{i}\right)^{2}\right]
$$

Untuk menentukan penduga kemungkinan maksimum dari parameter-parameter $\beta_{0}$, $\beta_{1}$, dan $\sigma^{2}$ yang dinotasikan dengan $b_{0}, b_{1}$, dan $\hat{\sigma}^{2}$, maka persamaan (2.7) ekivalen dengan

$$
\ln L\left(\beta, \sigma^{2}\right)=-\left(\frac{n}{2}\right) \ln 2 \pi-\left(\frac{n}{2}\right) \ln \sigma^{2}-\left(\frac{1}{2 \sigma^{2}}\right) \sum_{i=1}^{n}\left(Y_{i}-\beta_{0}-\beta_{1} X_{i}\right)^{2}
$$

Dengan menurunkan fungsi kemungkinan terhadap setiap parameter $\beta_{0}, \beta_{1}, \sigma^{2}$, 
118 Elvi Yati dkk.

diperoleh

$$
\begin{aligned}
& \frac{\partial \ln L}{\partial \beta_{0}}=0 \Rightarrow \frac{1}{\hat{\sigma}^{2}} \sum_{i=1}^{n}\left(Y_{i}-b_{0}-b_{1} X_{i}\right)=0, \\
& \frac{\partial \ln L}{\partial \beta_{1}}=0 \Rightarrow \frac{1}{\hat{\sigma}^{2}} \sum_{i=1}^{n}\left(Y_{i}-b_{0}-b_{1} X_{i}\right) X_{i}=0, \\
& \frac{\partial \ln L}{\partial \sigma^{2}}=0 \Rightarrow-\frac{n}{2 \hat{\sigma}^{2}}+\frac{1}{2 \hat{\sigma}^{4}} \sum_{i=1}^{n}\left(Y_{i}-b_{0}-b_{1} X_{i}\right)^{2}=0 .
\end{aligned}
$$

Penyelesaian persamaan $(2.9)-(2.11)$ adalah sebagai berikut.

$$
\begin{aligned}
b_{0} & =\bar{Y}-b_{1} \bar{X}, \\
b_{1} & =\frac{\sum_{i=1}^{n} Y_{i}\left(X_{i}-\bar{X}\right)}{\sum_{i=1}^{n}\left(X_{i}-\bar{X}\right)^{2}}, \\
\hat{\sigma}^{2} & =\frac{\sum_{i=1}^{n}\left(Y_{i}-b_{0}-b_{1}\right)^{2}}{n} .
\end{aligned}
$$

Sehingga diperoleh penduga model regresi linier sederhana adalah $\hat{Y}=b_{0}+b_{1} X$.

Pada model $Y=X \beta+\varepsilon$, persamaan (2.8) dapat ditulis dalam bentuk

$$
\ln L\left(\beta, \sigma^{2}\right)=-\left(\frac{n}{2}\right) \ln 2 \pi-\left(\frac{n}{2}\right) \ln \sigma^{2}-\left(\frac{1}{2 \sigma^{2}}\right)(Y-X \beta)^{t}(Y-X \beta)
$$

di mana $\frac{\partial \ln L}{\partial \beta_{i}}=0 \Rightarrow b=\left(X^{t} X\right)^{-1}\left(X^{t} Y\right)$.

\section{Transformasi Box-Cox}

Transformasi Box-Cox adalah transformasi pangkat pada variabel tak bebas di mana variabel tak bebasnya bernilai positif. Box dan Cox mempertimbangkan kelas transformasi berparameter tunggal, yaitu $\lambda$ yang dipangkatkan pada variabel tak bebas $Y$, sehingga transformasinya menjadi $Y^{\lambda}$, dimana $\lambda$ adalah parameter yang perlu diduga.

Prosedur transformasi Box-Cox pada analisis regresi linier sederhana untuk model $\mathbf{Y}=\mathbf{X} \beta+\varepsilon$ dapat dilakukan dalam dua bentuk transformasi. Menurut [2], transformasi pertama adalah:

$$
W_{i}(\lambda)=\left\{\begin{array}{c}
\left(\frac{Y_{i}^{\lambda}-1}{\lambda}\right), \lambda \neq 0 \\
\ln \left(Y_{i}\right), \lambda=0
\end{array}, \quad i=1,2, \cdots, n\right.
$$

Dari [5], diperoleh transformasi kedua berdasarkan $W_{i}(\lambda)$, dengan

$$
V_{i}(\lambda)=\left\{\begin{array}{c}
\left(\frac{Y_{i}^{\lambda}-1}{\lambda \hat{Y} \lambda-1}\right), \lambda \neq 0 \\
\hat{Y} \ln \left(Y_{i}\right), \lambda=0
\end{array}\right.
$$

di mana

$$
\hat{Y}=\sqrt[n]{Y_{1} Y_{2} \cdots Y_{n}}=\left(\prod_{i=1}^{n} Y_{i}\right)^{\frac{1}{n}} .
$$

merupakan rata-rata geometrik dari $Y_{1}, Y_{2}, \cdots, Y_{n}$. 
Transformasi $Y$ menjadi $W$ mengakibatkan model persamaan linier dalam notasi matriks menjadi $\mathbf{W}=\mathbf{X} \beta+\varepsilon$. Transformasi $Y$ menjadi $V$ mengakibatkan model persamaan liniernya dalam notasi matriks menjadi $\mathbf{V}=\mathbf{X} \beta+\varepsilon$. Dengan demikian, prosedur utama transformasi Box-Cox adalah menduga parameter transformasinya yaitu $\lambda$. Salah satu metode yang dapat digunakan dalam pendugaan parameter $\lambda$ pada Transformasi Box-Cox adalah Metode Kemungkinan Maksimum.

Dalam model regresi linier $\mathbf{V}=\mathbf{X} \beta+\varepsilon$ diperoleh fungsi kemungkinan sebagai berikut.

$$
L\left(\beta, \lambda, \sigma^{2}\right)=\left(2 \pi \sigma^{2}\right)^{-\frac{n}{2}} \exp \left[-\frac{1}{2 \sigma^{2}} \sum_{i=1}^{n}\left(V_{i}-\beta_{0}-\beta_{1} X_{i}\right)^{2}\right]
$$

Persamaan (3.3) ekivalen dengan

$$
\ln L=-\frac{n}{2} \ln \left(2 \pi \sigma^{2}\right)-\left(\frac{1}{2 \sigma^{2}}\right)(V(\lambda)-X \beta)^{t}(V(\lambda)-X \beta),
$$

dengan demikian

$$
\frac{\partial \ln L}{\partial \beta}=\frac{\partial\left[-\frac{n}{2} \ln \left(2 \pi \sigma^{2}\right)-\left(\frac{1}{2 \sigma^{2}}\right)(V(\lambda)-X \beta)^{t}(V(\lambda)-X \beta)\right]}{\partial \beta}=0 .
$$

Sehingga

$$
\Leftrightarrow\left(X^{t} X\right) \beta=X^{t} V(\lambda) \Leftrightarrow b=\left(X^{t} X\right)^{-1} X^{t} V(\lambda)
$$

Selanjutnya,

$$
\frac{\partial \ln L}{\partial \sigma^{2}}=\frac{-n}{2 \sigma^{2}}+\frac{(V(\lambda)-\hat{V}(\lambda))^{t}(V(\lambda)-\hat{V}(\lambda))}{2\left(\sigma^{2}\right)^{2}}
$$

di mana

$$
\begin{aligned}
& \hat{V}(\lambda)=X b=X\left(X^{t} X\right)^{-1} X^{t} V(\lambda) \\
& \Leftrightarrow \hat{\sigma}^{2}=\frac{(V(\lambda)-\hat{V}(\lambda))^{t}(V(\lambda)-\hat{V}(\lambda))}{n}=\frac{R S S(V(\lambda))}{n},
\end{aligned}
$$

di mana $R S S(V(\lambda))=(V(\lambda)-\hat{V}(\lambda))^{t}(V(\lambda)-\hat{V}(\lambda))$ merupakan jumlah kuadrat sisaan dari $V(\lambda)$.

Penduga kemungkinan maksimum $\hat{\lambda}$ dari $\lambda$ merupakan nilai yang memaksimumkan fungsi kemungkinan maksimum. Maka, $\hat{\lambda}$ memaksimumkan

$$
\begin{aligned}
\ln L & =\frac{-n}{2} \ln (2 \pi)-\frac{n}{2} \ln \left[\frac{R S S(V(\lambda))}{n}\right]-\frac{n}{2 R S S(V(\lambda))}[V(\lambda)-\hat{V}(\lambda)]^{t}[V(\lambda)-\hat{V}(\lambda)] \\
& \propto \frac{n}{2} \ln \left[\frac{R S S(V(\lambda))}{n}\right]
\end{aligned}
$$

$\hat{\lambda}$ meminimumkan $\frac{n}{2} \ln \left[\frac{R S S(V(\lambda))}{n}\right] \Leftrightarrow \hat{\lambda}$ diperoleh dengan menentukan nilai $\lambda$ yang meminimumkan

$$
R S S(V(\lambda))=[V(\lambda)-\hat{V}(\lambda)]^{t}[V(\lambda)-\hat{V}(\lambda)] .
$$

Penaksiran parameter $\lambda$ yang biasa dilakukan yaitu menentukan nilai $\lambda$ pada kisaran nilai tertentu. Biasanya $\lambda$ yang dipakai yaitu dari kisaran $(-2,2)$ atau $(-1,1)$. 
120 Elvi Yati dkk.

\section{Pembahasan}

Data yang digunakan dalam penelitian ini adalah data sekunder yang diperoleh dari website http://archive.ics.uci.edu. Data terdiri dari 90 pengamatan, dengan satu variabel bebas dan satu variabel tak bebas. Variabel bebas $(X)$ adalah umur penderita hepatitis yang berusia 30 - 50 tahun dan variabel tak bebas $(Y)$ adalah level bilirubin seorang penderita hepatitis.

\subsection{Analisis Data Awal}

Dengan menggunakan software SPSS 17 diperoleh model persamaan regresi sebagai berikut

$$
Y=0,454+0,024 X
$$

dengan $X$ adalah umur dan $Y$ adalah level bilirubin.

Pengujian asumsi normalitas menghasilkan nilai signifikansi 0,000 lebih kecil dari 0,1, maka disimpulkan data tidak menyebar normal. Pengujian asumsi homogenitas menghasilkan nilai signifikansi 0,000 lebih kecil dari 0,1, maka disimpulkan ragam data tidak homogen. Pengujian asumsi linieritas menghasilkan nilai signifikansi 0,213 lebih besar dari 0,1, maka disimpulkan bahwa antara variabel bebas $(X)$ dan variabel tak bebas $(Y)$ tidak terdapat hubungan yang linier.

Berdasarkan model regresidi atas, diperoleh selang level bilirubin yaitu 1, $174-$ $-1,654$. Nilai ini tentu tidak sesuai dengan nilai rujukan level bilirubin dewasa. Oleh karena itu, perlu dilakukan transformasi Box-Cox untuk memperoleh model regresi yang sesuai mengenai hubungan antara umur dan bilirubin pada seseorang.

\subsection{Transformasi Terhadap Variabel Tak Bebas (Y)}

Pada penelitian ini dilakukan transformasi $Y^{\lambda}$ terhadap variabel tak bebas $(Y)$ dengan langkah-langkah sebagai berikut :

(1) Menentukan range $\lambda$

Range $\lambda$ yang diambil adalah $(-2,2)$ dengan nilai

\begin{tabular}{|c|c|c|c|c|c|c|c|c|c|}
\hline No. & 1 & 2 & 3 & 4 & 5 & 6 & 7 & 8 & 9 \\
\hline$\lambda$ & 2 & 1,5 & 1 & 0,5 & 0 & $-0,5$ & -1 & $-1,5$ & -2 \\
\hline
\end{tabular}

(2) Menghitung $\hat{Y}=\left(Y_{1} Y_{2} \ldots Y_{n}\right)^{\frac{1}{n}}$

(3) Menghitung $\hat{Y}^{\lambda-1}$ untuk tiap harga $\lambda$

Nilai $\hat{Y}^{\lambda-1}$ untuk tiap harga $\lambda$ ditampilkan dalam tabel berikut

\begin{tabular}{|c|c|c|c|c|c|c|c|c|c|}
\hline$\lambda$ & 2 & 1,5 & 1 & 0,5 & 0 & $-0,5$ & -1 & $-1,5$ & -2 \\
\hline$\hat{Y}^{\lambda-1}$ & 1,1265 & 1,0614 & 1,0000 & 0,9422 & 0,8877 & 0,8364 & 0,7880 & 0,7425 & 0,6995 \\
\hline
\end{tabular}

(4) Menghitung $V_{i}(\lambda)$

Diperoleh nilai $V_{i}$ untuk tiap harga $\lambda$ dengan $i=1,2,, 90$. 
(5) Regresikan antara $V$ dan $X$, sehingga diperoleh JKS Diperoleh nilai JKS sebagai berikut

\begin{tabular}{|c|c|c|c|c|c|c|c|c|c|}
\hline$\lambda$ & 2 & 1,5 & 1 & 0,5 & 0 & $-0,5$ & -1 & $-1,5$ & -2 \\
\hline$\hat{Y}^{\lambda-1}$ & 1603,05 & 437,862 & 147,536 & 65,0742 & 38,6102 & 30,1490 & 29,5105 & 34,5212 & 46,5506 \\
\hline
\end{tabular}

(6) Tentukan $\lambda$ yang mempunyai JKS terkecil Nilai JKS terkecil adalah 29,5105 pada $\lambda=-1$.

(7) Melakukan transformasi data menggunakan $\lambda$ dengan JKS terkecil Dengan $\lambda=-1$ dilakukan transformasi $Y^{-1}$, artinya data awal $Y$ dipangkatkan dengan -1 yang diberi simbol dengan $Y^{\prime}$.

\subsection{Analisis Data Hasil Transformasi}

Pada tahap ini dilakukan regresi terhadap variabel tak bebas hasil transformasi $\left(Y^{\prime}\right)$ dengan variabel bebas $(X)$, sehingga diperoleh model persamaan regresi yang baru sebagai berikut

$$
Y^{\prime}=1,589-0,015 X
$$

dengan $X$ adalah umur dan $Y^{\prime}$ adalah level bilirubin.

Pengujian asumsi normalitas menghasikan nilai signifikansi 0,969 lebih besar dari 0,1 , maka disimpulkan data menyebar normal. Pengujian asumsi homogenitas menghasikan nilai signifikansi 0,785 lebih besar dari 0,1 , maka disimpulkan ragam data homogen. Pengujian asumsi linieritas menghasilkan nilai signifikansi 0,067 lebih kecil dari 0,1 , maka disimpulkan terdapat hubungan yang linier antara variabel bebas $(X)$ dan variabel tak bebas $(Y)$.

Dari hasil uji asumsi dasar terhadap data hasil transformasi, diperoleh bahwa data hasil transformasi tersebut telah memenuhi ketiga asumsi. Sehingga, model yang cocok untuk hubungan antara umur dan level bilirubin adalah $Y^{\prime}=1,589-$ $0,015 X$. Model regresi ini memberikan nilai Adjusted R Square sebesar 0, 026. Nilai ini menyatakan bahwa pengaruh variabel bebas $(X)$ terhadap variabel tak bebas $(Y)$ sangat kecil. Untuk model regresi ini diperoleh selang level bilirubin yaitu 0,8391,139. Nilai ini sesuai dengan nilai rujukan level bilirubin dewasa karena terletak pada selang $0,1 \pm 1,2 \mathrm{mg} / \mathrm{dL}$.

\section{Kesimpulan}

Data statistika dengan model regresi yang baik pada analisis regresi linier sederhana adalah data yang memenuhi asumsi-asumsi dasar regresi. Apabila asumsiasumsi tersebut tidak dipenuhi, maka dapat dilakukan transformasi terhadap data, salah satunya transformasi Box-Cox. Transformasi Box-Cox merupakan transformasi pangkat terhadap variabel tak bebas, yaitu $\lambda$ yang dipangkatkan terhadap $Y$ dengan bentuk transformasi $Y^{\lambda}$. Pendugaan parameter $\lambda$ dapat dilakukan dengan Metode Kemungkinan Maksimum, dengan tujuan mendapatkan jumlah kuadrat sisaaan yang minimum. 
122 Elvi Yati dkk.

\section{Daftar Pustaka}

[1] Bain, L.J dan M. Engelhardt. 1997. Introduction to Probability and Mathematical Statistics. Second Edition. PWS-KENT, Boston

[2] Drapper, N.R dan H. Smith. 1992. Analisis Regresi Terapan. PT. Gramedia, Jakarta

[3] Ispriyanti, D. 2004. Pemodelan Statistika dengan Transformasi Box-Cox. Jurnal Matematika dan Komputer. Vol.7 No.3

[4] Natrella, M. 2012. NIST/SEMATECH e-Handbook os Statistical Method. U.S Commerce Department's Technology Administration, USA

[5] Rawling, J.O, S.G Pantula dan D.A Dickey. 1998. Applied Regression Analysis : A Research Tool. Second Edition. Springer-Verlag, New York

[6] Siegel, S.1992. Statistik Nonparametrik. PT. Gramedia, Jakarta 